\section{Does development assistance reduce violence? Evidence from Afghanistan}

\section{Tiffany Chou}

$\mathrm{C}$ urrent counterinsurgency (COIN) doctrine emphasizes the role of benign development assistance as a key component in any campaign to enhance security in conflicted and postconflict regions. ${ }^{1}$ As a consequence, significant resources have been spent on rebuilding Afghanistan's institutions and livelihoods with the intention that such projects achieve both conventional development goals and donors' security objectives. Since 9/11, the U.S. government has appropriated nearly US\$20.3 billion for governance and development in Afghanistan, on top of the security-related and human costs of the war. ${ }^{2}$ The questions of when, where, and how development assistance builds stability are especially relevant to policymakers as the military intervention in Afghanistan enters its tenth year and international donors begin to shift their attention to other conflicted areas such as the Middle East and Africa.

While counterinsurgency researchers and practitioners appear to agree on the importance of popular support in determining the outcome of insurgent conflicts, the question of how to gain it is still debated. "Hearts and minds" proponents argue that the government can win civilian support by addressing grievances, thus reducing the "demand" for rebellion. Others argue that rebels, like secular criminals, might be more sensitive to the opportunity costs and potential payoffs of rebellion. This would be especially true in weakly governed places where the state cannot successfully "buy off" potential rebels, either through legitimate work opportunities or other income transfers, nor can they effectively utilize a cooperative populace's information. So far, the empirical evidence on the relative importance of grievances ("demand") compared to employment/income-generation ("supply") as motivations for insurgent violence has been somewhat mixed. Rather than analyzing the underlying reasons for insurgency, this article explores a more fundamental question: Does spending lower violence? ${ }^{3}$

While counterinsurgency is almost as old as war itself, there has been relatively little empirical research into whether these reconstruction efforts have generated security improvements as intended. Recent empirical evidence suggests that this strategy of combining military operations with civilian development has been somewhat successful in Iraq. ${ }^{4}$ This article, however, looks at reconstruction and violence in Afghanistan and finds that those efforts have ambiguous effects on conflict. For each of three reconstruction programs (the Afghan National Solidarity Program, USAID's Local Governance and Community Development Program, and the U.S. military's Commander's Emergency Response Program), project spending does not statistically reduce, nor increase, the level of rebel violence.

However, the difference in results between the U.S. military's CERP and the two other programs suggests that aid conditionality is an essential, but currently underemphasized, prerequisite for stability-enhancing development. The theoretical model predicts stark differences in effectiveness between aid that is contingent on community cooperation (conditional aid) and aid that is not: Only conditional aid reduces insurgent violence. Development projects provided independent of information-sharing have no effect on violence because

they are valuable to the community regardless of whether the government or rebels are in control; hence, they cannot induce information-sharing on the margin. Out of the three programs examined here, only CERP practices conditionality and hence is the only one predicted to have violence-reducing potential. The empirical results are consistent with this conjecture as CERP is the only one to have consistently negative, if imprecisely estimated, effects on rebel violence.

While overall spending does not appear to be "winning hearts and minds," there is some heterogeneity across different types of spending. In particular, I find preliminary evidence that small-scale CERP projects might be more effective at reducing violence than larger ones. This finding is consistent with the theoretical prediction that projects or places where the government is more effective at providing services should exhibit stronger violence reduction. However, these estimates are imprecise and only small-spending delivered through the U.S. military demonstrates this effect; small-scale development through USAID's LGCD program does not appear to have much effect on rebel activity.

The next section outlines a model of counterinsurgency with an emphasis on two empirically testable hypotheses regarding the relationship between development spending and insurgent violence. (Interested readers can see the full mathematical model in the Appendix or in Berman, Felter, and Shapiro, 2011.) This is followed by a section that discusses both the military records on violence and the institutional details of the three different development programs used to empirically test those hypotheses. The empirical sections present the main findings, and this is followed by a concluding section, endnotes, references, and the Appendix. 


\section{Theoretical model}

What distinguishes an insurgency from a traditional interstate military conflict? Both are contests between armed parties in pursuit of political power, but unlike conventional armed conflict, insurgencies emphasize the pivotal role of noncombatants. Civilians, who are generally unarmed and may not even share political ideologies with the rebels, are crucial to the success of insurgent campaigns because they can provide actionable information that makes military operations more effective. Rather than being merely passive observers of a conflict, the populace is an active player in insurgencies, one that responds swiftly to both state and rebel actions. In a conflict between the government and rebel forces, the local population can either share its information with the government (and other allied forces) or not. The key insight from the theoretical model is that the government can induce information sharing by providing basic necessities or other goods and services. ${ }^{5}$

The three actors in the strategic interaction are Government $(G)$, Rebels $(R)$, and Community $(C)$. Government seeks to minimize costs through a combination of violence mitigation and service provision while rebels maximize their utility by choosing a level of violent action. The community's key action is to choose whether or not to share information with government. Payoffs to each of the players are determined by whether $G$ or $R$ is in control.

The key assumption in the model is that government service provision is only valuable to the community when $G$ is in control at the end of the game. While all government services improve the local community's wellbeing, only conditional services are able to affect $C$ 's decision to share information and, in equilibrium, will be violence-reducing. Empirically speaking, a regression of violence on reconstruction spending should have a negative coefficient (denoted as hypothesis $\mathrm{H}_{1}$ ).

Aid conditionality seems a rather extreme assumption since it cannot literally be true of certain projects (e.g., infrastructure). However, it is a necessary condition for spending to be violence-reducing in the model. Intuitively, unconditional service provision does not affect the community's behavior since it benefits in both states of the world. Since spending by traditional development agencies is not conditional on cooperation, the model predicts stark differences in the violence-reducing potential between the military's CERP and the other, unconditionally provided, aid programs. While the model's prediction about unconditional spending is quite clear, this should be treated as a positive statement, one about a concrete implication of the model, rather than a normative one about what policymakers should do. Government can still provide unconditional services to increase the community's welfare, even if it does not induce information sharing. As a practical matter, some reconstruction projects, like paving roads or building power plants, provide logistical benefits to government as well as to locals.

The basic model treats all spending uniformly; an additional dollar for digging wells or paving roads increases the community's wellbeing by the same amount. The second hypothesis concerns the relative effectiveness of particular types of service provision. Projects that provide higher marginal utility to the community ("more bang for the buck") should have stronger violence-reducing effects (denoted as $\mathrm{H}_{2}$ ). More effective spending provides higher marginal benefits to the community; in equilibrium, this makes it more likely to share information, which in turn decreases insurgent violence. The empirical interpretation is that small projects, which are quicker to implement and more adaptable to community needs, should exhibit stronger violence-reducing effects than large ones. The definition of small projects is based on program guidelines, which will be discussed in more detail later on.

\section{Data on insurgent violence and reconstruction programs}

To create a measure of insurgent activity, I use declassified incident records from the U.S. military's Combined Information Data Network Exchange (CIDNE) database. These records consist of 60,075 events of "significant activity" (SIGACT) from April 2002 through January 2010. Each event record comes with date, time, attack type, and geographic coordinates, which allow each incident to be precisely geo-located. These data are then converted into a detailed district-month panel of insurgent activity.

A few limitations of the violence data are worth discussing. First, a SIGACT, by definition, must be insurgent-initiated; events initiated by coalition or Afghan forces are not included. Also, to the extent that rebels attack civilians or conduct criminal activity, SIGACTs will undercount true violence experienced by the population. As the model is framed as rebels attacking the government, SIGACTs are the appropriate measure of insurgent activity to test the theoretical predictions. In practice, civilians are likely to care about all types of violence and insecurity in their community, not just the ones targeted at government forces, and neither the model nor the data capture this. Second, SIGACTs can vary in scale and complexity, ranging from direct fire incidents to improvised explosive devices (IEDs), and since there is no information about the damage caused or units involved in these attacks, all event types are just pooled together. ${ }^{6}$

As a measure of government service provision, I use project expenditures from each of three different reconstruction programs (NSP, LGCD, and CERP) to create a district-month panel of reconstruction spending. These programs all fund a variety of projects types though project selection is likely to differ based on the incentives of the different stakeholders and involved parties.

Started in 2003, the National Solidarity Program (NSP) is intended to help individual communities build and manage their own development projects. Logistically, NSP allocates block grants, based on the number of households, to individual rural areas and aids a Community Development Council (CDC) in identifying and developing projects to use those funds. The NSP data cover almost US\$680 million in project expenditures spread across 316 out of Afghanistan's 398 districts. 
The second development program is USAID's LGCD, which seeks to improve Local Governance (LG) and Community Development (CD) in insecure areas. ${ }^{8}$ LGCD projects are also community-initiated and driven since proposals can be brought up and approved through the local CDC, but they lack the explicit block grant funding scheme of NSP. In contrast to NSP, LGCD is relatively new with initial projects starting in 2007. While LGCD itself is active in other regions of Afghanistan, the data are limited to just projects in the South and East regions.

The final reconstruction program for which I have data is the U.S. military's Commander's Emergency Response Program (CERP). As its name suggests, CERP is intended to allow commanders to provide "urgent, small-scale, humanitarian relief, and reconstruction projects and services that immediately assist the indigenous population." However, CERP projects do not have an explicit maximum, and they range in size from small condolence payments to construction of major roads. Since 2004, CERP has appropriated almost US\$2.64 billion in Afghanistan. ${ }^{10}$ While CERP is the longest running of the three reconstruction programs examined here, district identifiers and project expenditures were only usable for four months in 2009-2010.

Using these data on individual project locations, dates, and costs, I construct a panel of reconstruction expenditures by uniformly spreading project spending over all days in which each project was active and then aggregating up to the district-month level. This spending measure is the main explanatory variable in the regression analysis. This implicitly assumes that spending is a viable measure of service provision. For a variety of reasons, this might not be the case in Afghanistan, which will be discussed further in the concluding section.

The sample means for the spending and violence variables are listed in Table 1. To account for size effects, both violence and spending measures are scaled by district population, and the regressions are also weighted by population. From April 2002 to January 2010, the average number of SIGACTs per month is 0.017 incidents per 1,000 people, or about 10.2 attacks annually in a median district of 50,000 residents. For comparison, this is about six times lower than in Iraq, which averaged about 0.098 attacks per month per 1,000 residents. Average monthly spending by NSP is about US\$0.23 per person while average LGCD and CERP spending is only half that (around US\$0.11 and US\$0.08 per capita, respectively). This is far less than in Iraq where CERP averaged almost US\$1.76 per person per month.

Empirical effect of reconstruction spending on insurgent violence

One methodological issue is worth discussing before moving to the empirical results. Traditional development programs like NSP are limited to operating in areas that are sufficiently safe for their civilian staff. In contrast, CERP and LGCD are intended be stability-enhancing, and program directors might strategically allocate resources to areas inherently prone to violence. This implies that a simple cross-sectional analysis of violence on reconstruction spending would find higher NSP spending in low
Table 1: Summary statistics

\begin{tabular}{|c|c|c|c|}
\hline & Observations & $\begin{array}{l}\text { Number of } \\
\text { of districts }\end{array}$ & Mean \\
\hline $\begin{array}{l}\text { Incidents per } 1,000 \\
(\text { Apr } 2002 \text { - Jan 2010) }\end{array}$ & 37,412 & 398 & $\begin{array}{l}0.0174 \\
(0.0867\end{array}$ \\
\hline $\begin{array}{l}\text { NSP spending (per capita) } \\
\text { (Apr } 2002 \text { - Jan 2010) }\end{array}$ & 29,704 & 316 & $\begin{array}{l}0.233 \\
(0.399)\end{array}$ \\
\hline $\begin{array}{l}\text { LGCD spending (per capita) } \\
\text { (Jul } 2007 \text { - Dec } 2009 \text { ) }\end{array}$ & 5,328 & 144 & $\begin{array}{l}0.109 \\
(0.487)\end{array}$ \\
\hline $\begin{array}{l}\text { CERP spending (per capita) } \\
\text { (Oct } 2009 \text { - Jan 2010) }\end{array}$ & 808 & 202 & $\begin{array}{l}0.0810 \\
(0.386)\end{array}$ \\
\hline - Large projects $(>\$ 50,000)$ & 808 & 202 & $\begin{array}{l}0.0271 \\
(0.298)\end{array}$ \\
\hline - Small projects $(\leq \$ 50,000)$ & 808 & 202 & $\begin{array}{l}0.0539 \\
(0.230)\end{array}$ \\
\hline
\end{tabular}

Notes: Incident records are from the CIDNE database. Means are weighted by Landscan population; standard deviations are in parentheses. LGCD is only active in the South and East. An observation is a district-month.

violence areas, but the reverse for CERP and LGCD spending. A simple positive correlation between, say, CERP spending and SIGACTs does not mean that reconstruction causes violence though as one would not have accounted for the fact that the kinds of districts that tend to receive CERP funds are also probably the most violent ones.

Rather than just simply comparing spending and violence across districts, the empirical method here compares violence and spending within districts. There are a variety of district-level characteristics that are likely correlated with insurgent activity, for example ethnic makeup, proximity to the border, or mountainous geography. These features make SIGACTs extremely persistent across time within any particular district, but comparing changes in violence to changes in spending removes these time-invariant district effects. ${ }^{11}$ These "first difference" regressions, which are the preferred specification throughout, are labeled FD in the tables to differentiate them from the simple ordinary least squares (OLS) that compare reconstruction and SIGACTs across districts. Since there may be strong seasonality or time trends in SIGACTs, the full specifications also include controls for the quarter and year of observation. ${ }^{12}$ In other words, the regression coefficients in the FD regressions are interpreted as the effect of an additional dollar per person in reconstruction spending 
on violence within individual districts and net of time effects.

Table 2 presents estimates of both the cross-sectional (OLS) and first-differenced (FD) regressions of insurgent violence on reconstruction spending for each of the three development programs. Looking first at the OLS columns, there is a very weak positive relationship between violence and spending for NSP and a noticeably stronger positive one for both LGCD and CERP. Places with high LGCD or high CERP spending tend to be more violent than those with low spending, but insurgent activity is not a strong predictor of whether a district receives NSP. This is consistent with the discussion above about how different types of programs target resources differently and reinforces the fact that we should be careful drawing conclusions from just a simple cross-sectional regression.

The adjacent FD columns estimate the same violence-on-spending regressions but account for a district's predisposition to violence. For NSP and LGCD, the spending coefficients are positive, meaning that districts that have large increases in spending experience increases in violence, but not statistically different from zero. Since neither program delivers aid conditionally, the model predicts that they will not be violence-reducing.

The spending coefficient for CERP, however, is negative, implying that increases in CERP spending predict decreases in SIGACTs. CERP is spent conditionally, and thus is the only program that, according to the model, should have a violence-reducing effect. While the coefficient on CERP is also not statistically different from zero, the estimated effect is relatively large. To put this in context, insurgent violence sharply increased between 2005 and 2006 as the militants regrouped and renewed attacks; in the data, the average monthly rate of violence increased by 0.011 SIGACTs per 1,000 residents. The spending coefficient of -0.011 means that an additional dollar per capita of CERP projects reduces violence by 0.01 SIGACTs per 1,000 residents, or enough to mitigate the entire increase in rebel activity between 2005 and 2006 (if the effect is indeed causal). While the standard errors for all three programs are all quite large, CERP is the only one that appears to result in economically meaningful reductions of violence.

The magnitude of CERP's effect is also remarkably similar to its effect in Iraq, even though the context and environmental conditions differ between the two countries. In Iraq, the spending coefficients for CERP were between -0.009 and -0.011 , surprisingly similar to the -0.011 in Afghanistan. ${ }^{13}$ Moreover, the aforementioned Iraq results were highly significant and very precisely estimated since that theater tracked CERP projects reliably over a much longer time period (almost five years, compared to just four months in Afghanistan). The availability of data in Iraq allow for more precise estimates than is possible here.

While there are multiple dimensions of nonlinearity, there is one particular dimension that bears mentioning. While CERP and LGCD have the stated function of enhancing "stability" - which is generally understood to mean the security of noncombatants - the theory and regressions were developed using violence directed
Table 2: Development spending and violence

\begin{tabular}{|c|c|c|c|c|c|c|}
\hline \multirow{2}{*}{$\begin{array}{l}y=\text { incidents } \\
\text { per } 1,000\end{array}$} & \multicolumn{2}{|c|}{ NSD spending } & \multicolumn{2}{|c|}{$L G C D$ spending } & \multicolumn{2}{|c|}{ CERP spending } \\
\hline & $O L S$ & $F D$ & $O L S$ & $F D$ & $O L S$ & $F D$ \\
\hline $\begin{array}{l}\text { Spending } \\
\text { (US\$/capita) }\end{array}$ & $\begin{array}{l}0.00090 \\
(0.00342)\end{array}$ & $\begin{array}{l}0.00116 \\
(0.00300)\end{array}$ & $\begin{array}{l}0.0164 \\
(0.0118)\end{array}$ & $\begin{array}{l}0.000246 \\
(0.00319)\end{array}$ & $\begin{array}{l}0.0387 \\
(0.0233)\end{array}$ & $\begin{array}{l}-0.0110 \\
(0.00967)\end{array}$ \\
\hline Year FE & & X & & X & & \\
\hline Quarter FE & & $\mathrm{X}$ & & $\mathrm{X}$ & & \\
\hline $\mathrm{R} 2$ & 0.000 & 0.002 & 0.002 & 0.005 & 0.004 & 0.003 \\
\hline Observations & 29,704 & 29,388 & 5,328 & 5,184 & 808 & 606 \\
\hline Number & 316 & 316 & 144 & 144 & 202 & 202 \\
\hline
\end{tabular}

of districts

Notes: Robust standard errors in parentheses, clustered by district. Regressions are weighted by population. An observation is a district-month. Sample is strongly balanced to include only districts that ever have NSP or LGCD as where appropriate. CERP projects count per 1,000 , rather than spending per capita, is the explanatory variable in the CERP columns. Quarter and year fixed effects (FE) are omitted from CERP spending regressions since there is only one year of data. Dependent variable (y) is insurgent events per 1,000 population as recorded by CIDNE. None of the coefficients are significantly different from zero at the 10 percent level.

against combatants as the outcome. In other words, SIGACTs are implicitly assumed to be proxy for district stability or government control. For example, there could be a nonlinear relationship between the observed outcome, SIGACTs, and unobserved rebel control simply because there are no military targets to attack in insurgent zones of control, nor would there be anyone around to record the incident. As government or coalition forces start to enter these insurgent strongholds, the number of SIGACTs could increase as the rebels are presented with more potential targets. Since the government sometimes expands into regions where it previously had little control, this could be viewed as a stability improvement even though reported violence is actually increasing. To examine this possibility, I divide districts using a composite index of stability and then estimate the violence-on-spending regressions within each stability category. However, splitting the estimation sample by stability does not qualitatively change the result that development spending is ineffective at reducing insurgent violence. ${ }^{14}$

\section{Effectiveness of small CERP projects}

I now turn to the second testable hypothesis $\left(\mathrm{H}_{2}\right)$ : Projects that provide higher benefit 
on the margin are more effective at reducing violence. To test this, I classify CERP projects as large or small based on administrative guidelines, and then repeat the analysis with small spending included separately from large spending. In this context, $\mathrm{H}_{2}$ implies that the coefficient on small spending is more negative than that for large spending.

Funding regulations for CERP allow small projects to be authorized and implemented regionally without seeking the approval of higher-ranking (and more remote) officers. More specifically, Standard Operating Procedures for CERP in Afghanistan allow battalion commanders to authorize projects of US $\$ 50,000$ or less. ${ }^{15}$ These smaller grants provide local commanders and aid officials more flexibility and responsiveness in meeting urgent community needs. Such projects are likely to be highly valued by the local population compared to larger ones with a long implementation time.

Table 3 explores $\mathrm{H}_{2}$ using CERP data, splitting spending using the US\$50,000 cutoff. In the first column, an additional dollar per person in small CERP projects reduces violence by 0.029 incidents per 1,000 residents, almost three times as large as the estimate on overall spending in Table 2 . In column 2, large spending is also negatively signed, but the coefficient, at -0.004 , is much smaller in magnitude than that for small projects. Column 3 includes both types of projects simultaneously, and the results are almost identical to when the two types are included individually. ${ }^{16}$ The standard errors are again quite large, and the coefficients on large and small spending are not statistically different $(\mathrm{p}=0.35)$. Given the lack of precision, these results provide weak evidence in support of $\mathrm{H}_{2}$. Small CERP projects appear to be almost twice as effective at reducing violence in Iraq compared to Afghanistan, where an additional dollar per capita in small projects reduced violence by 0.053 incidents per 1,000 residents. Similarly, large projects in Iraq were less effective at reducing violence than smaller ones, with an estimated coefficient of $-0.008 .{ }^{17}$ For brevity, similar results from LGCD program regulations are omitted. ${ }^{18}$

While none of the three overall spending regressions appear to be strongly violence-reducing, the difference in estimates between big and small projects suggests that other dimensions of project heterogeneity might be useful in guiding future aid practices or theoretical developments. However, different categorical cuts of the spending data do not provide much insight about which project types are more effective in improving district stability since the estimates all displayed the same lack of precision as the aggregate regressions.

\section{Conclusion}

This article tests two empirical hypotheses on current counterinsurgency theory in the Afghan context. The results suggest that development aid in Afghanistan, whether it comes from the U.S. military, USAID, or the Afghan government itself, has not been effective in reducing insurgent attacks. While overall service provision did not appear
Table 3: Small versus large CERP projects

$\begin{array}{llll}\begin{array}{l}y=\text { incidents } \\ \text { per 1,000 }\end{array} & \text { (1) } & \text { (2) } & \text { (3) } \\ & & & \\ \text { Spending (small) } & -0.0291 & - & -0.0290 \\ & (0.0267) & & (0.0268) \\ \text { Spending (large) } & - & -0.00363 & -0.00306 \\ & & (0.00390) & (0.00389) \\ \text { R2 } & 0.006 & 0.000 & 0.006 \\ \text { p-value for } \beta \text { (small)= } \beta \text { (large) } & - & - & 0.0348 \\ \text { Observations } & 606 & 606 & 606 \\ \text { Number of districts } & 202 & 202 & 202\end{array}$

Notes: Robust standard errors in parentheses, clustered by district. Regressions are weighted by population. An observation is a district-month. Sample is strongly balanced to include only districts that ever have spending data from CERP. "Small" projects are those that spend US\$50,000 or less. None of the coefficients are significantly different from zero at the 10 percent level.

to reduce violence, the analysis suggests that small CERP projects might be a useful tool to reduce violent insurgency.

Given the vast amount of resources, both monetary and human, that the international community has committed to rebuilding Afghanistan, a natural question to ask is: Why does CERP spending not appear to be effective in reducing insurgent activity in Afghanistan when it did so in Iraq? The results suggest three potential explanations. First, the conditionality of aid is a necessary, and possibly overlooked, condition underlying the theoretical model. While the majority of CERP implementers in Afghanistan report practicing conditionality, a significant minority do not. ${ }^{19}$ Aid conditionality is the military's official policy for CERP, but the importance of conditionality implies that future efforts to use reconstruction as a tool to increase stability could benefit from a greater emphasis or stronger guidelines about aid provision and community cooperation.

Second, the lack of violence-reduction raises questions about program effectiveness: Perhaps money spent is not translating into services provided. The model abstracts away from the efficacy of government provision of services in the sense that higher levels of spending imply higher service provision. In other words, service provision is measured as money spent, not as physical outputs or civilians helped. In a world where reconstruction and service provision by the state signals competent and committed governance, dollars spent should be closely related to services provided, and hence effective at inducing information-sharing and improving 
security. This connection might be tenuous in an institutionally weak environment such as Afghanistan where monitoring is absent or extractive rent-seeking behavior is commonplace. These weaknesses can dampen or even reverse the effect of reconstruction on stability should they provide more rents for insurgents to capture ${ }^{20}$ or signal incompetent or ambivalent governance. ${ }^{21}$ Large construction projects, in particular, could suffer severely from this issue as they involve multiple levels of contractors and subcontractors who could be colluding or otherwise acting anti-competitively.

Third, the model reflects only static interaction. But in a dynamic model noncombatants would consider their future wellbeing, and development would increase support for the government only if it signaled a permanent shift in improved governance tomorrow. In the Afghan context the mismanagement of development funds might be signaling the opposite. Future efforts to rebuild contested and postconflict areas should not necessarily focus on spending more money, but rather on using it more effectively.

\section{Notes}

Tiffany Chou is an economist at the Office of Economic Policy, Department of the Treasury. She may be reached at $<$ tiffany.chou@treasury.gov $>$. This essay is adapted from research conducted while she was a graduate student at the University of San Diego, California. The findings, interpretations, and views expressed in this article are solely those of the author and do not reflect those of the federal government, including the Department of the Treasury.

1. This is explicitly stated in the COIN Field Manual: "Durable policy success requires balancing the measured use of force with an emphasis on nonmilitary programs ... COIN programs for political, social, and economic well-being are essential to developing the local capacity that commands popular support when accurately perceived." (U.S. Army, 2006, Section 2-5).

\section{SIGAR (2012).}

3. Hearts and mind: Gurr (1970); Horowitz (1985). Criminals: Becker (1968). Opportunity cost/payoffs: Grossman (1991); Fearon(2008), Mixed: Fearon and Laitin (2003) find that civil war is predicted by low income per capita and difficult terrain, both of which are indicative of poor state capacity and low opportunity cost of rebellion. However, Berman, Felter, Shapiro, and Callen (2011) show that employment rates are actually positively correlated with insurgent violence in Iraq, the Philippines, and Afghanistan. But in Afghanistan, rebel attacks seem to increase after coalition-induced civilian casualties, suggesting that the "supply" of insurgent activity is somewhat responsive to government actions (Condra, Felter, Iyengar, and
Shapiro, 2010).

\section{Berman, Shapiro, and Felter (2011).}

5. Noncombatants: U.S. Army, Section 13 (2006). Actionable information: Kalyvas (2006); Kaldor (2007). Populace as active player: Galula (1964); Popkin (1979). Share information or not: Berman, Shapiro, and Felter (2011). Other interpretations of "hearts and minds" theory argue that noncombatants are influenced not by improved governance but by grievances allayed, jobs provided, or because their leaders are coopted, and that the consequential act of noncombatants is not information sharing but active resistance to rebel activity, taxation or recruitment (Gurr, 1970; Horowitz, 1985). Nevertheless, all these models share the implication that development spending reduces violence.

6. For a full discussion of measurement error issues, including an analysis between how observed SIGACTs are related to underlying Afghan stability perceptions, see Chou (2011).

\section{MRRD (2007).}

8. USAID (2010).

9. U.S. Army, Ch.4 (2009).

10. $\operatorname{SIGAR}(2011)$.

11. In particular, including lagged SIGACTs on the right-hand side yields a coefficient estimate of 0.9 , with a standard error of approximately 0.02 , in all specifications for all reconstruction programs, but does not materially change the results.

12. Patterns of violence over the sample are discussed in more detail in Chou (2011).

13. Berman, Felter, and Shapiro (2011).

14. Full results are in Chou (2011).

\section{USFOR-A, paragraph 5.K (2009).}

16. Large spending can be thought of as a proxy for the presence of military forces. However, this similarity in coefficients suggests that the unobserved location of military units does not strongly bias the results. 
17. Berman, Felter, and Shapiro (2011).

18. Full results are in Chou (2011).

19. Berman, Felter, and Shapiro (2011).

20. Wilder (2009); Crost, Felter and Johnston (2012).

21. Rashid (2008).

\section{References}

Beath, A., F. Christia, R. Enikolopov, and S. Ahmad Kabuli. 2010. "Randomized Impact Evaluation of Phase-II of Afghanistan's National Solidarity Programme (NSP): Estimates of Interim Program Impact from First Follow-Up Survey." Mimeo. Washington, D.C.: World Bank. July.

Becker, G.S. 1968. "Crime and Punishment: An Economic Approach.” Journal of Political Economy. Vol. 76, No. 2, pp. 169-217.

Berman, E., J.N. Shapiro, and J.H. Felter 2011. "Can Hearts and Minds be Bought? The Economics of Counterinsurgency in Iraq." Journal of Political Economy. Vol. 119, No. 4, pp. 766-819.

Berman, E., J.H. Felter, J.N. Shapiro, and M. Callen. 2011. “Do Working Men Rebel? Insurgency and Unemployment in Afghanistan, Iraq, and the Philippines.” Journal of Conflict Resolution. Vol. 55, No. 4, pp. 496-528.

Chou, T. 2011. Essays in Labor Economics. Doctoral dissertation. Department of Economics. University of California, San Diego.

Condra, L.N., J.H. Felter, R.K. Iyengar, and J.N. Shapiro. 2010. "The Effect of Civilian Casualties in Afghanistan and Iraq." NBER Working Paper 16152. July.

Crost, B., J.H. Felter, and P. Johnston. 2012.” Aid Under Fire: Development Projects and Civil Conflict." http://patrickjohnston.info/materials/AUF.pdf.

Fearon, J. 2008. “Economic Development, Insurgency, and Civil War," pp. 292-328 in E. Helpman, ed. Institutions and Economic Performance. Cambridge: Harvard University Press.

Fearon, J.D. and D.D. Laitin. 2003. “Ethnicity, Insurgency, and Civil War.” American Political Science Review. Vol. 97, No. 1, pp. 75-90.

Galula, D. 1964. Counterinsurgency Warfare: Theory and Practice. New York: Praeger.

Grossman, H.I. 1991. “A General Equilibrium Model of Insurrections.” American Economic Review. Vol. 81, No. 4, pp. 912-921.

Gurr, T. 1980. Handbook of Political Conflict. New York: The Free Press.

Horowitz, D.L. 1985. Ethnic Groups in Conflict. Berkeley, CA: The University of California Press.
Kalyvas, S. 2006. The Logic of Violence in Civil War. Cambridge: Cambridge University Press.

[MRRD] Ministry of Rural Reconstruction and Development. 2007. National Solidarity Programme Operational Manual, Version V. http://www.nspafghanistan.org/default.aspx?sel=16 [accessed 13 April 2012].

Kaldor, M. 2007. New and Old Wars: Organized Violence in a Global Era. 2nd edition. Cambridge, UK: Polity Press.

Popkin, S.L. 1979. The Rational Peasant: The Political Economy of Rural Society in Vietnam. Berkeley, CA: The University of California Press.

Rashid, A. 2008. Descent into Chaos: The United States and the Failure of Nation Building in Pakistan, Afghanistan, and Central Asia. New York: Viking.

Skaperdas, S. 1996. "Contest Success Functions.” Economic Theory. Vol. 7, No. 2, pp. 283-290.

[SIGAR] Special Inspector General for Afghanistan Reconstruction 2011. “Commander's Emergency Response Program in Laghman Province Provided Some Benefits, but Oversight Weaknesses and Sustainment Concerns Led to Questionable Outcomes and Potential Waste." SIGAR Audit-11-7. January.

[SIGAR] Special Inspector General for Afghanistan Reconstruction 2012. January 30 , 2012 Quarterly Report to Congress. http://www.sigar.mil/pdf/quarterlyreports/ 2012-01-30low.pdf [accessed 13 April 2012].

[USAID] United States Agency for International Development. 2010. Local Governance and Community Development (LGCD) Fact Sheet. June. http://afghanistan.usaid.gov/documents/document/document/1020 [accessed 13 April 2012].

United States Army. 2006. Counterinsurgency. FM 3-24. December.

United States Army. 2009. Commander's Guide to Money as a Weapons System. April. http://usacac.army.mil/cac2/call/docs/09-27/toc.asp [accessed 13 April 2012].

[USFOR-A] United States Forces-Afghanistan. 2009. Money As A Weapon System Afghanistan (MAAWS-A), Commander's Emergency Response Program, Standard Operating Procedures. USFOR-A Pub 1-06. December.

Wilder, A. 2009. "Losing Hearts and Minds in Afghanistan." In Afghanistan, 1979-2009: In the Grip of Conflict. Tufts University, Middle East Institute. December. http://sites.tufts.edu/feinstein/2009/losing-hearts-and-minds-inafghanistan. [Accessed 30 April 2012].

\section{Appendix: Formal model}

Players, actions, and payoffs

There are three players in the game, denoted $G, R$, and $C$. The key state of the game that determines payoffs is whether $G$ or $R$ has control at the end, denoted by a binary 
variable $a$ where $a=1$ if $G$ is in control and $a=0$ if $R$ is in control. The community has political norms regarding rebel control, $n$, which are conceptualized as a utility penalty if $G$ is in control at the end of the game.

The community's sole action is to choose a level of information-sharing $i \in[0,1]$. The rebels also only have one action, to choose a level of violence $v \geq 0$, which targets the government but still negatively affects the community. The government has two actions: It can combine benign social services, $g \geq 0$, with active operations to mitigate violence, $m \geq 0$

The community's payoffs are as follows: If $a=1$ (government control), it receives secular consumption $c$ and government-provided services $g$ but also experiences a penalty for having shared information $n$; if $a=0$ (rebel control), it still receives consumption $c$ but also suffers from violence $v$. The payoff function for $C$ is:

$$
U_{C}(c, g, v, n, a)=a \cdot u(c+g-n)+[1-a] \cdot u(c-v),
$$

where $u(\cdot)$ is a well-behaved utility function. Note that a key assumption is that $g$ is conditional; the government can and will only provide services if it is in control at the end of the game.

The rebels' goal is to impose costs on government. Violent actions benefit rebels according to the function $A(v)$ but only if they are in control at the end of the game. Violence costs rebels $B(v)$ regardless of the ending state. The payoff function for $R$ is:

$$
U_{R}(v, a)=[1-a] \cdot A(v)-B(v),
$$

where $A(v)$ and $B(v)$ are both $\mathrm{C}^{2}$ and increasing. $A(\cdot)$ is concave while $B(\cdot)$ is convex. Assume that no violence results in no damage: $A(0)=0$.

Both the community and rebels are expected utility maximizers. The government seeks to minimize a combination of violence and costs. If $R$ has control at the end of the game, $G$ suffers damage $A(v)$, otherwise it is unharmed by rebel violence. Both violence mitigation $m$ and service provision $g$ incur costs, defined by $D(m)$ and $H(g)$, respectively, regardless of which player is in control at the end. The government's total cost function is:

$$
C_{G}(v, m, g, a)=[1-a] \cdot A(v)+D(m)+H(g)
$$

Cost functions $D(\cdot)$ and $H(\cdot)$ are $\mathrm{C}^{2}$, increasing and convex, and scaled such that $D(0)=H(0)=0$. To rule out the case where mitigation is never effective, assume that $A\left(n_{u}\right)>D^{\prime}(0)$. Intuitively, this condition says that even in the "worst case scenario" (i.e. areas with the highest proclivity toward violence), it costs less to provide a tiny amount of counterinsurgency effort than it does to suffer full damage from rebel violence. Hence, it is always in the government's interest to provide nonzero counterinsurgency effort.

The final component of the model is how $G$ converts mitigation $m$ and information $i$ into control. Let $p$ denote the probability that $a=1$. $G$ can combine mitigation and information to increase its probability of winning control according to:

$$
p=\operatorname{PR}(a=1)=h(m) \cdot E(i),
$$

where $h(m): \mathrm{R}^{+} \rightarrow[0,1]$ is a "contest success function" (Skaperdas, 1996). Higher COIN effort $m$ increases the probability that $G$ is in control, but this mitigation also faces decreasing returns; $h(m)$ is increasing but concave. $h(0)=0$ and $h(m) \rightarrow 1$ as $\mathrm{m} \rightarrow \infty$. Note that information sharing is necessary but not sufficient for control: if $i=0$, then $p=0$, but $i=1$ does not guarantee that $p=1$.

Description of the game

The game has four stages but strategic interaction only occurs in Stage 2 and Stage 3. In Stage 1, Nature draws norms $n \sim U\left[n_{L}, n_{U}\right]$, and this parameter is revealed only to $C$. The support of $n$ is assumed to be wide enough that neither $G$ nor $R$ can fully determine the outcome of the game through his actions alone. ${ }^{1}$ In Stage 2, $G$ and $R$ simultaneously move. In Stage 3,C observes the actions of the previous stage $\{v, m, g\}$ and chooses its level of information sharing. Finally, Nature draws the final state $n \sim$ bernoulli $(p(m, i))$, and payoffs to $G, R$, and $C$ are determined.

Equilibrium

Solve for the subgame perfect Nash equilibrium via backward induction. The community's objective is to choose $i$ to maximize:

$$
\begin{aligned}
E U_{c}(c, g, v, n, a) & =E(a) \cdot u(c+g-n)+[1-E(a)] \cdot u(c-v) \\
& =p \cdot u(c+g-n)+[1-p] \cdot u(c-v) \\
& =h(m) \cdot i \cdot u(c+g-n)+[1-h(m) \cdot i] \cdot u(c-v)
\end{aligned}
$$

Since this function is linear in $i$, the only solutions are on the boundaries. ${ }^{2} C$ will choose to share information if $u(c, g, n)>u(c-v)$; otherwise, it will not share at all. Since $u(\cdot)$ is monotonically increasing, this implies that $C$ 's best response is:

$$
i *\left\{\begin{array}{l}
1 \text { if } g-n>-v \\
0 \text { if } g-n<-v
\end{array}\right.
$$

Given the distributional assumption about $n$, this implies that:

$$
\operatorname{Pr}\left(i^{*}=1\right)=\operatorname{Pr}(n<g+v)=\left(g+v-n_{L}\right) /\left(n_{U}-n_{L}\right)=f \cdot\left(g+v-n_{L}\right),
$$


(C) www.epsjournal.org.uk - Vol. 7, No. 2 (2012)

where $f=1 /\left(n_{U}-n_{L}\right)$. Substituting this into the definition of $p$ results in:

(1) $p^{*}(m, v, g)=h(m) \cdot i^{*}=h(m) \cdot f \cdot\left(g+v-n_{L}\right)$.

Turning to the previous stage of the game, $G$ and $R$ will simultaneously optimize, knowing that $C$ 's actions will result in the final state $a=1$ with probability $p^{*}$ defined by equation (1). $R$ 's problem is simply to choose violence to maximize:

$$
E U_{R}(v, a)=[1-E(a)] \cdot A(v)-B(v)=\left[1-p^{*}(m, g, v)\right] \cdot A(v)-B(v) .
$$

The first-order condition for $v$ is:

$$
\begin{aligned}
\delta E U_{R} / \delta v & =\left[1-p^{*}\right] A^{\prime}(v)-A(v) \delta p^{* / \delta} v-B^{\prime}(v) \\
& =\left[1-p^{*}\right] A^{\prime}(v)-A(v) h(m) f-B^{\prime}(v)=0
\end{aligned}
$$

which results in a best-response function $v^{*}(m, g)$. Differentiating implies that $v^{*}$ is decreasing in both its arguments. Holding $m$ constant, rebels respond to increased service provision with lower violence. Similarly, rebels respond to higher COIN effort by lowering violence, holding $g$ constant.

$G$ 's problem is to choose both $g$ and $m$ to minimize:

$$
\begin{aligned}
E C_{G}(v, m, g, a) & =[1-a] \cdot A(v)+D(m)+H(g) \\
& =\left[1-p^{*}(m, g, v)\right] \cdot A(v)+D(m)+H(g) .
\end{aligned}
$$

The first-order condition with respect to $m$ is:

$$
\delta E U_{G} / \delta m=-A(v) \delta p^{*} / \delta m+D^{\prime}(m)=0 .
$$

The first-order condition with respect to $g$ is:

$$
\delta E U_{G} / \delta g=-A(v) \delta p^{* / \delta} g+H^{\prime}(g)=0
$$

Solving the first-order conditions provide best-response functions $m^{*}(g, v)$ and $g^{*}(m, v)$. Implicitly differentiating implies that both COIN effort and service provision are increasing in $v$ and that, for a given level of rebel activity, mitigation and services are complements. The subgame perfect Nash equilibrium is defined by the bestresponse functions $m^{*}(g, v), g^{*}(m, v), v^{*}(m, g)$, and $i^{*}$ derived above.

\section{Appendix notes}

1. More specifically, $n_{L} \leq v+g \leq n_{U}$.
2. Trivial solutions occur in the case where $h(m)=0$ or $g-n=-\mathrm{v}$. In either case, any value of $i$ is optimal. Since $m=0$ is never optimal and $h(m)$ is increasing, there are no other values of $m$ that might yield Case 1 . 